Suite 210, Media, PA 19063, USA

Tel: +1 4842348000

E-mail: esullivan@

ariasystems.com

\title{
The customer lifecycle in SaaS environments - Interview with Ed Sullivan of Aria Systems
}

\section{Ed Sullivan}

is the CEO and founder of Aria Systems, the leading provider of on-demand billing and customer management solutions Ed founded Aria in 2002. Prior to Aria, Ed was the founder and president of LaserLink.net, a Virtual Internet Service Provider that was acquired by Covad Communications in 2000 .

Keywords: customer management, SaaS, customer lifecycle, monetization model, online billing, Web 2.0

Abstract When you consider the entire lifecycle of a customer in a SaaS environment, managing customer interactions is at least as important as managing financial transactions. Ed Sullivan of Aria Systems discusses the stages of customer lifecycle within a SaaS environment and how a robust billing platform can help manage customer relations. Journal of Digital Asset Management (2008) 4, 260-268. doi:10.1057/dam.2008.21

MM: We're here with Ed Sullivan, CEO of Aria Systems. Ed, give us a little background in terms of you. If you would, just your job function and a short summation of your career.

ES: This is my fourth startup. I'm an engineer by background.

Prior to founding Aria, I was founder of a very large affiliate for a branded virtual ISP called LaserLink. We managed the Internet Service Providers (ISPs) for Gateway, Compaq, Amway, IBM and Univision Online. I sold that business to Covad Communications in 2000.

It was through that experience that I realized that billing is hard to do. There are a lot of things that people overlook when deciding to manage subscription-based services and distribution of digital content. Distribution of any content is painful if not done properly. MM: Just give us a background in terms of Aria Systems - maybe starting with the corporate name and story. Then go into the history and now the nature of its business.

ES: The name of the company is Aria Systems. We are incorporated in Delaware but we reside just outside of Philadelphia, PA. Our website is AriaSystems.com.

We provide billing and customer management software. We deliver that software as a service. That means our customers don't have to manage any of the data or infrastructure. We offer highfunction software. Software that - before us - would cost six or seven figures to purchase. And then a similar range of costs to operate and maintain.

We offer our clients that high-end billing functionality. We charge them on a pay-as-theygo model. That means that we charge them based on how much of the software they use. MM: So that we could put this into context, as a provider of a service - software as a service or a capability as service - do you then compete with enterprise software providers of similar high-function software?

ES: Yes.

MM: If that's the case, which are some of those companies that you compete with?

ES: In terms of functionality, we see a range of competitors. The most direct competitor to us would be a telco-based subscriptionmanagement software company like Portal, Amdocs or Convergys. But we also see competitors like PayPal, for instance. Especially in the Web 2.0 world where people are using PayPal to manage customers.

We also have seen merchant account providers and accounting systems. From our perspective, they only really solve one kind of component or one of the functions in the customer lifecycle. The key thing about Aria is that we uniquely address the needs of a recurring relationship throughout the customer lifecycle, versus just solving one problem. 
A lot of times we'll see modified shopping carts that are internally built and attached to a merchant account. In turn, they're attached to an accounting system.

But a shopping cart, at its core, isn't designed around managing a recurring, ongoing relationship - this is much more difficult thing to execute than a one-time transaction.

MM: This gets into basically a transactionmanagement capability. Specifically, you've framed the notion of a customer lifecycle. Could you take us through the stages of a customer lifecycle?

ES: We basically break our customer lifecycle management into several buckets which we, collectively, call our "monetization platform".

The first compartment is customer acquisition. When a customer comes in, most registration software or homegrown shopping carts allow you to take basic demographic information - the credit card information and apply a charge against it.

The Aria system at that point is a little bit different. We have the ability to integrate with marketing software.

That's a big part of customer acquisition that's often ignored. How are they getting to you? What partners? What direct sales efforts? What marketing activities did you do to get that customer in?

The next thing that Aria does is it allows you to offer plans or rates and services based on the product that you're offering. We have a lot of customers in the Software-as-a-Service that sell based on the seat or based on a flat-rate subscription. But they might have a tiered offering where they're trying to maximize their revenue yet also address several layers of the market segment where they can get the small businesses and move their way up.

Our system also has the ability to allow our clients to differentiate on those flat-rate services. But also, to maximize monetization by enabling things like usage-based types of transactions. Our system has a pretty cool usage-based engine, which is like the second or third part of this six-part thing. Usage tracking.

Under acquisitions, picking the plans, if you want to monetize on these micro-transactions and micro-payments, how do you want to do that? You need a metering and rating infrastructure there that's flexible, definable and not constrained by the telco paradigm of "How much time are you connected to a service?" Or "How many bytes of data are you using?"

We're billing for many areas of digital entertainment. We're in the gaming industry where we're billing for virtual items that are transacted real-time. We're also, in software, billing for how many seats or how many transactions occur in a software. That's the monetization part, through customer acquisition.

The next step is after you acquire the customer you need to be able to turn them off or provide the service to them. Shopping cart software, a lot of times, is built around managing an inventory, fulfilling and shipping things. In the digital rights it's basically your inventory is digital. You have to maintain entitlement and track entitlement to either one service or multiple services appropriately - and enforce your business logic.

An example would be a popular hybrid model. Somebody might download a client for a software, but then also go to a server out on the internet to update those data, refresh those data or have access to data. There's like a client server aspect of it - even if the client is just a web browser.

We need to maintain entitlement to that through some kind of authentication. When the customer signs up we would go out and turn that service on or turn multiple layers of services on, or even potentially mash-up of services from different providers, and bundle them together for our client. Then they could charge either on a flat rate, subscription-based, or on usage elements from each of those providers.

MM: If I understand you right so far, Ed, the first one was customer acquisition - with an emphasis on closing the feedback loop in terms of lead generation.

ES:Yes.

MM: The second one was really a dynamic processing or offer management. There you have the ability to offer digital services or capabilities in a lot of different configurations. Probably driven by some set of policies and rules, but ultimately for maximizing the profitability of any one transaction - given the nature of the buyer. ES: That's right. We kind of call that our "activation engine." The first one is acquisitions. The next one is activation. So turning on plans and services based on that business logic. 
MM: Right. The third dimension that you've mentioned here - the customer lifecycle management - is use-tracking. Use in terms of being able to keep track of what they're consuming. That will correspond to some sort of micro-payment capability.

Then the fourth you'd indicated - I would characterize it as "provisioning." That starts with authentication and then entitlement. Then a mash-up or a provisioning of whatever it is that they're authorized to consume.

ES: Yes. The way I'd characterize is, I'd have that in the second bucket. Basically, there's an acquisition activation that includes the provisioning and the plan creation. Then the third is the usage tracking and rating.

The fourth one would be the actual billing. As you can see, we call ourselves billing and customer management. But the billing's only one real piece of what we do. We actually divide billing into several segments. As you can tell, I'm an engineer by training. I guess the way of thinking about things is - I break them down into smaller problems. That's, in fact, how we build our software.

We divide billing into a couple of things. Billing we define as calculation, presentment, collections, remittances and reconciliation. In order to have what I call a high-function billing system you need to be able to do all of those things in an automated fashion so that your clients can scale their businesses.

A lot of our competitors - and I gave a range of different competitors - may only do one of those things well. Even if they do it, they don't automate it.

For instance, there are software companies and web-based companies out there that are invoicing companies. You calculate your invoice, you enter the amount into their web service and they will deliver that electronically to your customer. They do the presenting piece.

We think that in order to really scale businesses and totally automate, you need to do all of those things. Calculation, presentation, collections, remittance and reconciliation. And you need to do them well.

That's Stage 4. Stage 5 is what we call "customer management" or "customer control." There are three layers to that. Layer number 1 is communication.
Again, this is my experience as an operator coming out. If you think about my ISP operator experience, I had 70 brands and 2.5 million subscribers. I saw that the best way to minimize those costs of customers - of owning the customers - is proactive outbound communication throughout the customer lifecycle. But making sure that you understood the good use cases and the not so good use cases.

An example of a good use case is, a customer comes in and I take their credit card and turn the service on and they never talk to me again.

An example of a less good use case - but I guess there's a silver lining... A customer comes in and they light the service. Midway in the cycle they want to upgrade or buy more. How do you handle that?

It's a good problem in that they want to give you more revenue. But the bad problem is that depending on how it's handled it can be a very costly interaction.

Then the third set of use cases is when people have disputes. A lot of my competitors talk about how they can do micro-transactions. Yes. We can do the micro-payments. The problem is closing the loop on the backside.

It's one thing to be able to do them. It's another thing to be able to handle the disputes around micro-transactions.

If somebody gets through and talks to you for 30 seconds on a dispute, on a line item or on an invoice, you basically lose any margin you had on that micro-transaction.

Proactive outbound communication is the first layer. Making sure that your system can automate those communication events throughout that customer's lifecycle. Understanding all of the positive use cases, but also understanding all of the not so positive use cases as well.

MM: When you speak about proactive outbound communication, you're talking not about your client, but your client's customer?

ES: That's right.

Well, it's a combination of my clients' customers and even potentially third parties.

For instance, if my client's customer hasn't paid - whether they be a consumer customer in B2B2C or a business customer in B2B2B we need to make sure that we're managing that entitlement and making sure that those third 
parties understand what their next steps are, related to that service.

MM: So you were saying the second phase of customer control entails what?

ES: It entails user self-service. Allowing all classes of users to solve their own problems. In our system, for most service providers, we have what we call high-frequency issues and longhandle-time issues.

MM: High-frequency issues and what?

ES: Long-handle-time issues.

MM: For some reason I didn't get the second part. Long what?

ES: Long handle time.

MM: Long handle time. Okay.

ES: An example of a high-frequency issue is that you want to change your user name or password. An example of a long-handle-time issue is that you're calling in and you want to have a service upgrade or a service downgrade. Or a dispute on your invoice.

The functionality of our user self-service is in the second layer. Customer management is the module. The three layers are communication, user self-service and then customer service.

On the user self-service, it's making sure that all of those high-frequency issues can be handled by the customers themselves. The next layer is, if they get through to a customer service representative or internal administrator. Making sure that that administrator can solve that problem quickly and right at the front level. Not have to escalate issues and not have to talk to the customer very long. It makes for a better customer experience and reduces operational costs.

MM: For the most part, solving customer issues — by the time they've escalated or triaged to a live operator - that's more than just billing or transaction management. That oftentimes requires that they tell a service representative to turn on or off or reconfigure some capability of whatever they're provisioning.

ES: Exactly. Being able to change a plan or service - and giving that power in an automated way to a low-level customer service representative - is really one of the main keys of what our software does.

MM: That then puts a much greater emphasis on your ability to integrate with other systems of action.

ES: That's right.
MM: Could you go into a little bit of detail there in terms of just as a quick footnote, how you do the mash-up or integrate with other systems?

ES: Sure. On the customer service side, here's an example. We have a client that runs a game out of San Francisco. It's a game in San Francisco. They have a call center in India and a call center in the Philippines.

Those customers there use our service to handle disputes around the billing aspect of it. They can turn things on and off.

We've also integrated with a piece of software called RightNow. I don't know if you're familiar with RightNow. RightNow is very good at managing the service elements.

On the telco side, if your phone's broken or you're in an area where a tower's bad, our software doesn't do a good job of tracking those types of issues from the service-provider's perspective. But RightNow software does an excellent job of that.

They can tell that there might be a generic issue in this part of the network. Or there might be a generic issue with this type of thing being distributed that it doesn't function well.

In the case of this game, when a customer signs up we go to RightNow and we say, "Ed Sullivan - with this user profile - is a user of the game, and has entitlement to the server and has this plan set up."

So if I call in for tech support relative to the service I'm using, they can answer my question. They can see if I'm entitled to the service first of all. In this particular case, they have entitlement-based customer support. There's a free version of the game and then there's a paid version of the game.

If you have the free version of the game, you can play the game but you can't get customer support. If you have the period version of the game, you can play the game. You can access an extended universe of the game with more features and functionality. But you also get customer service.

MM: Let's go to the sixth phase of your customer lifecycle model.

ES: The sixth phase is reporting and analytics.

Tying all of this stuff together. Being able to see what plans or services are coming in. How many USD did I make in transactions through 
my payment processor? Or how many euros?

How many rubles? How many yen?

We're getting financial information out of there and we're getting marketing information out of the system. Where are these leads coming from? What promo codes are they entering in? What plans are they buying? What's most effective? What are my usage statistics?

We had one game launched where it was a free-to-play, but they would pay for items. Some customers were spending $\$ 150$ a day buying items in the game. Getting those data out.

Then some of the stuff that's on our roadmap that we don't offer today, but we have it in beta right now. Looking at metadata around the service.

For instance, I was talking about the efficiency of our tool to solve problems quickly. One of the things we do is to track views and clicks of CSRs.

Imagine you're a software provider and you have a call center in India and a call center in the Philippines. The call center in India might be to solve a problem. Let's say the problem is service upgrade. They want to buy more seats.

If you see that the call center in India is solving that problem in ten views and three clicks, whereas the call center in the Philippines is doing it in two views and two clicks, you might want to do some training for the call center in India to increase their efficiency.

MM: What else along those lines do you see in terms of emerging as applications for this customer lifecycle management?

ES: One other piece at the end that we're integrating with is, we're integrating with the accounting system. We're taking the data and putting it into SAP, in one case. NetSuite in another case. Oracle Financials in another case.

It's the ability to interchange financial data seamlessly. I think there's kind of a gap in the SOA world. There are well-known protocols for us to exchange information on the PCP-IP stack that we can use for financial information. But it would be cool if there were a standardized way to send general ledger information and inventory information to accounting systems.

There've been a couple of attempts, but its not very well used or adopted or very well thought out.
MM: As you bring this capability to market, what are the major market segments that you're addressing initially?

ES: There are three segments initially. Then we plan to go very horizontal. We think we can be the oracle of billing. If you look at the publicly traded, large software companies, I think there are 30-ish software companies that have reached over a billion in revenue. And two or three of them are billing companies. I think that four of them are CRM companies.

So you have Salesforce in the CRM space. We think that we're positioned to be the Salesforce in the billing space. One of the Salesforce equivalents in the billing software space.

We're focusing our outbound efforts on three key areas, right now. They are software as a service... We are also SaaS. But we're additionally focusing on other SaaS providers.

MM: Makes total sense.

ES: The second is entertainment and media. We have online gaming, content and things like that.

Then the third is telecommunications. We're making great strides in telecom and some of the other unique telecom kinds of services. Where they're mashing together GPS and infrastructure, to provide cool services.

For instance, we have a client called Zoombak that tracks your kids. You give them a little device and you can track where your kids or pets are. That states who we're integrated with. And we're using Vodafone's infrastructure in the UK. That's who we're also integrated with.

Those are the three focus areas for us right now. SaaS, media-and-entertainment and then telecom.

MM: So your primary point of entry into the companies in those areas would be probably at the business development or product side of their house, which are looking for specific capabilities. Is that correct?

ES: Yes. We're finding that it really depends on what stage they are in their development. We have this model that we use to decide where we go. We call it the monetization-maturity model (Figure 1).

At the lowest level, all they care about is getting the money and getting customers. We solve that problem for them. Typically, those issues come up in the product-development stage. When they're first launching the product. 


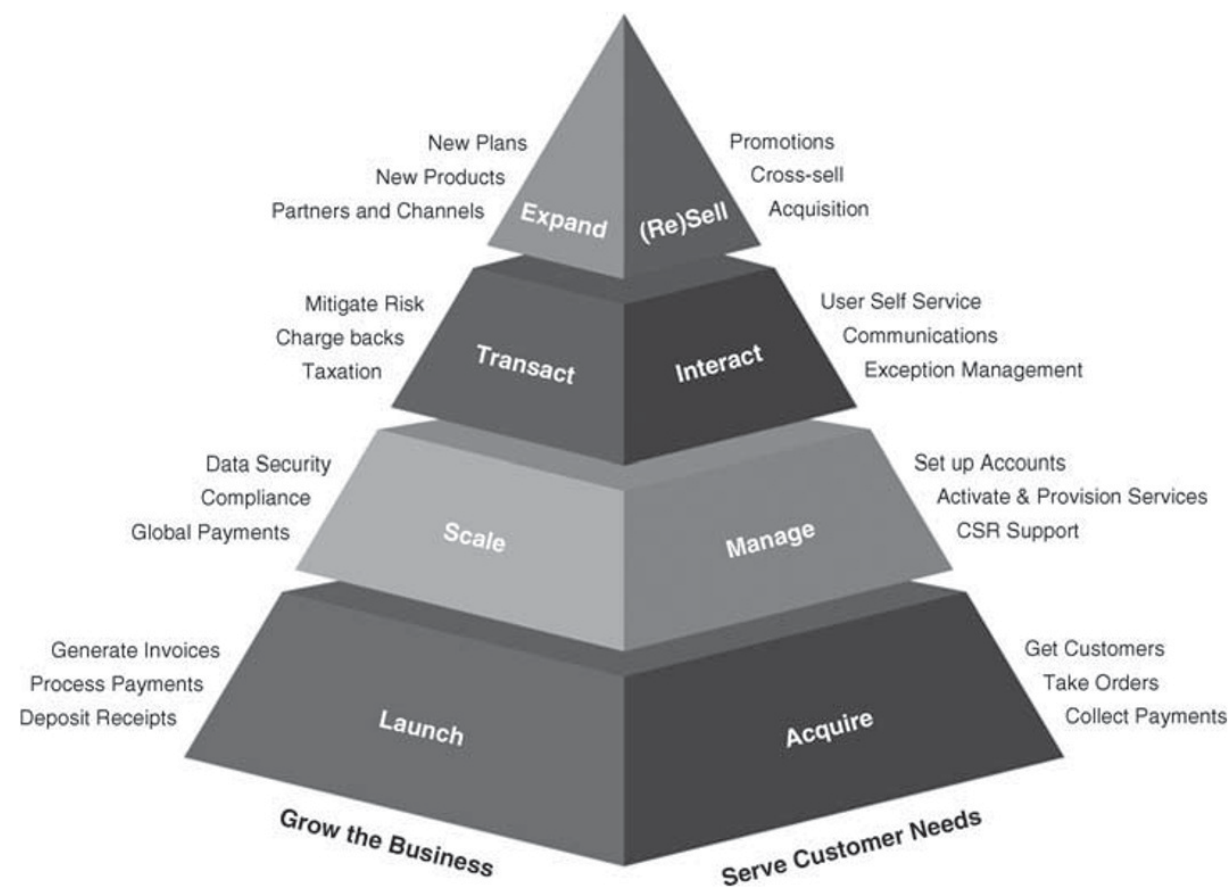

Figure 1: A pyramid of needs for subscription-based businesses

If they're early on in their cycle, that's when we talk to them. We try to go in on the barking side or the product-development side.

The next level up is security and compliance. That's usually the CFO or CIO or CTO. After something's launched or is about to launch and they're looking to get scale, they're beginning to worry about their compliance and taking credit cards. They're beginning to worry about their European Safe Harbor Compliance, and managing multi-continent transactions.

Then at the next level, they're starting to think about things like SAS70 and SarbanesOxley. Well, some of our clients are publicly traded companies. But even companies that aren't publicly traded and have it in their goals to be acquired by a publicly traded company, or $\mathrm{VC}$ or some kind of other private equity they need to make sure that they're compliant with the issues.

Then the next layer up is extending that product. Coming out with new price and plans. Having flexibility. A lot of billing systems once you put them out there and create their pricing and plans and things like that, it's very hard to add additional features and additional functionality. Or different price plans.

If you're doing a flat rate bill for a service and you're charging by the number of seats, it's very hard to change that business model to count how many transactions you have in a piece of software, and bill based on that element.

The limitation on a lot of cases isn't that the network elements of the service provider can't handle that, but it's the billing system at its core that can't handle that. They either can't handle the micro-transactions and micro-payments or they can't handle the ability to do flat rate billing and users-based billing, and do a hybrid model.

MM: That's the top of the pyramid? ES: Yes.

MM:You brought up something really interesting. The notion of managing transactions and customer relationships across a "monetization and maturity model." That tracks really well with another model that we use. An information maturity model for marketing operations.

More specifically, the thing that I find fascinating about what you just expressed... 
I find the notion that managing the transaction becomes the primary constraint on business growth and transformation. You might have a business strategy that could drive top-line revenue. But because you can't manage the transaction or re-engineer the transaction, you can't unlock that opportunity.

ES: No. We see that as the tragic flaw or the Achilles heel of a lot of these Web 2.0

businesses. There are some really unique ways of how they want to monetize their product or service. But it's managing those transactions and managing those interactions in a scalable fashion, where stuff breaks.

MM: There was a great theorist - actually a master practitioner - Adrian Slywotski, who's written a number of books. But the one that really kind of lands that whole concept is something called "Value Migration." I think another one was called "Profit Zones."

The idea was, he was the guy who really came out and started to develop a very comprehensive, robust description of what he calls a "business model" or a "business design."

He says that, fundamentally, a business model is really about two things. One, your value-add. What you bring to a market. And value-capture. Specifically, the devices that you have for valuecapture.

Specifically, he was getting into the idea that a lot of companies leave a lot of value on the table because they don't have the appropriate mechanisms in place to capture it.

ES: I've never heard of him, so I'm fascinated. MM: Specifically, in a lot of our interviews with other kinds of technical innovation leaders or thought leaders or market leaders, in terms of who are really driving transformational technology or disruptive technology to market, oftentimes it's just that - what you said. "How they get paid."

On an abstract level, according to your monetization-maturity model, at the end of the day you're selling a transformation of a business model. The ability to constantly re-engineer, tweak and refine the business model - with an emphasis on the value-capture.

ES: Yes.

I gave a talk at this year's SaaS Summit. Very similarly, in a converging way, I concluded my talk with... Especially when you consider in the software space, which was the audience I was addressing, here.

Behind-the-firewall, on-premise providers tend to think of their software as their business. When you move to a service-provider aspect, your software is no longer your business. Your customer experience is your business. And your monetization mechanisms are your business. It's a very different way of thinking.

MM: Yes. Almost a flat-world — round-world idea.

ES: Yes.

MM: One last thing, as we move towards what we'll call the "future proofs" or "future-forwardlooking comments" and so on.

I just read a book called "The Making of Second Life." It was the corporate history - a four- or five-year history of the development of second life as a user-generated world. The emphasis was on the pivotal role that digital property rights and user-generated worlds have.

Specifically, the emergence of the Linden dollar as a way of managing micro-payments.

Could you speak to some of the underlying technical or business issues as they relate to customer relationships or trade relationships based on micro-payments?

ES: With our system, we've separated micropayments from micro-transactions. We think they're very distinct types of transactions or interactions. Meaning, if you look at the Lyndon and how the Lyndon happens, one of the reasons they came up with the Lyndon was that the economic cost of doing transactions in realworld dollars versus virtual-world dollars was cost-prohibitive to them.

That meant you couldn't come out and buy a cool T-shirt in second life that in real-world dollars might be a fraction of a penny. One thousandth of a cent.

MM: Right. Economists refer to that as the "transaction cost."

So the transaction costs of the deal far exceeded the actual dollar value of the deal much less the profit of it.

ES: Correct.

I think that a lot of the future development is going to be in two things. What we call "payment processors" and then "payment methods." A payment method can be effectively - a currency. You have the aggregators - the PayPal and the electronic 
wallet providers. They try to aggregate these transactions.

So we built our system to be processorindependent and also currency-independent. That means we can transact in Lyndon if we can hook up to a payment processor that will accept Lyndon as a currency. There are none of those yet. But if you look at things like PayPal and maybe a little bit of what Amazon's doing with their DebtPay, they're actually going to end up being a de facto wallet.

MM: This gets into another development I'd like you to speak to. Again, I'd like to reference it in terms of a popular science fiction book by Cory Doctorow. He wrote a book called, "Down And Out In Disney World."

It's set in the near-term future and essentially describes how each of us is completely embedded in a [inaudible] mesh for a mobile or wireless environment. In the course of this new pattern of how we live, work and play as described in the book, there are two basic accounting systems.

There are two financial systems that prescribe or envelop us as individuals. There's the actual monetary system of dollars and cents, and you buy stuff. Then there's a reputation management system where in the language of the book they call it "Whuffie."

As you do good things, like free up a parking place for somebody, they throw you ten or 15 Whuffie. Or if you're rude to somebody, they take away ten or 15 Whuffie from you.

So as you kind of go through life, you're constantly collecting or expending social credits. Whuffie. That has the net effect of whether you get the good seat at the restaurant or get all these other kinds of soft privileges based on your reputation.

So we're beginning to see how Arthur C. Clark envisioned satellites and we made them and how the creators of Dick Tracy envisioned the walkietalkie wristwatch. Science fiction often informs the next thing for engineers to go build out.

Specifically, as you talk about micro-payments and micro-transactions, could you speculate on how you'd see your system, or systems like yours, facilitating the emergence of this second economy, based on Whuffie dollars — for lack of a better term?

ES: I actually love the analogy. I haven't read that book either. I just ordered it on Amazon as you were talking. There's the combination of the financial system and then the combination of the reputation system.

If you think about it today, effectively the three credit card company interchanges do with Visa, MasterCard, American Express in combination with their merchant banks... they are the reputation system. They are underwriting that reputation.

They are coming out and saying Ed Sullivan is a good guy and has a very high probability of being able to pay you that $\$ 30$.

MM: Even in more direct terms, Ed. If you go to eBay, you've got that TrustMark.

ES: Right.

MM: That's the really conceptual big breakthrough. That is the actual quantification of trust in real markets, by category.

ES: Wow. Let me see.

Basically, who was going to provide that reputation as a service? If I think about how our system's architected, we're already integrated, using that same kind of parallel between the payment processors.

We're integrated with most of the major banks in the world, to go out... If somebody gives us a credit card number, we go out and figure out electronically — within a millisecond — if that card that's being presented really belongs to that person. That's number 1 - is there fraud?

I see parallels all over the place. Even in a reputation as a service system, if I want to go out and check your reputation I've got to make sure that it's not somebody trying to pretend that they're you. How do I prevent fraud in that credential?

Then the limit of that reputation. "Yes, he's good, but don't trust him for more than a month or for more than a $\$ 100$ purchase" or whatever it is.

MM: So that almost gets into a social media or a social networking version of the FICO store. ES: Yes.

I think we're inventing a really cool business here. I don't know if anyone's doing it. I'll have to go read that book. I'm actually not going to go to Amazon now - I'm going to go to Borders and try to buy it.

MM: There's actually an e-mail company. I can't remember the name of it. But it's basically an add-on or plug-in to the Microsoft Exchange Server or group-wise, and your 
Outlook client. It creates an internal Whuffie system. So if I get a bogus e-mail from you, I'll take away ten points from you. But if I get a really crisp, clear e-mail from you, I'll give you some Whuffie.

They're creating an at-a-boy acknowledgment, or a social credit system for e-mails that improve productivity of the intended recipient.

ES: That's similar to del.icio.us, for instance. Right? If you look a keyword into del.icio.us, to say "Okay. I'm interested in some brand new thing on laptop computers." Or Lenovo's X61. You would be able to go in and see what the highest-frequency discussions are around that kind of thing.

MM: Yes. Fabulous.

One last thing I'd like you to comment on. In my conversations and interviews with other technology providers - and more specifically innovation leaders in their field... has emerged the notion of multichannel marketing analytics.

Multichannel marketing analytics has - like your lifecycle model - distinct phases. The first phase entails a monitoring function. Think of it as raw, censored data in the web space. And more specifically, in the social networking space.

If I call in to a call center, the software would enable the teleservice representative to say, "Oh. Here's his LinkedIn profile. Here's his FaceBook profile. Here's his Zing profile. Here's his blog."

It federates in or syndicates in, and it reconditions published, public 2.0 kind of stuff into the customer interaction. So even though you don't know me from Adam, as a function of being able to link me to my published digital persona or footprint you're able to enrich not only the interaction, but also immediately transfer or syndicate in from that all kinds of demographic and psychographic information. That then starts the whole engagement process. ES: What we do probably isn't as flashy as that. Nor what we're envisioning. But if you consider our competitors — most are allon-premise competitors - their limitation is that they don't have the ability to aggregate these data, or make intelligent alerts or choices about this data.

We're working on this intelligence back-end, where we can not only give our clients very meaningful data to what they do and what their businesses are, but... Imagine if you are a new Web 2.0 service and through us you can do a sort of figure exchange and see. Here are ten other or 100 other or 1,000 other Web 2.0 service providers and what their first 60 days of transactions look like. What their churn looks like. And what the probability is that somebody's going to go off or churn off your system if they elicit misbehavior.

So maybe it's not as exciting as that, but that - I think - is where the real opportunity is. As all of these features - all of the software moves through the internet. Where you're going from hundreds of point solutions installed to a single instance of this priceless data that you can aggregate, anonymize, aggregate and offer to the customers.

MM: Fabulous.

Ed, it's come to about that point in time when we need to roll up our interview. Are there any last comments? Any last ideas you'd like to summarize with?

ES: Just reiterating — we really think that there's a big gap in the market. Especially when you look at things that don't really think of the entire customer lifecycle. Managing these interactions is just as important as managing the financial transactions.

Software companies — especially companies that come from technologists - tend not to think about all of this lifecycle management, which is the way that we thought about our core product.

MM: Again, I want to thank you very much. 